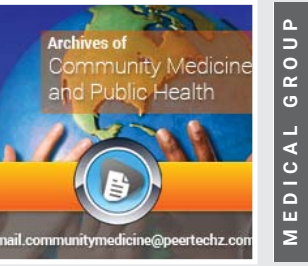

\title{
Maternal caffeine consumption and childhood behavioural and neurocognitive development: A
}

\section{focused narrative review}

Received: 06 June, 2021

Accepted: 11 June, 2021

Published: 15 June, 2021

*Corresponding author: Jack E James, PhD, Reykjavík University, Menntavegur 1, 101 Reykjavík, Iceland, Tel: + 354599 6200; E-mail: jack@ru.is

Keywords: Pregnancy outcomes; Caffeine; Coffee; Childhood behaviour; Neurocognitive development; Animal experimental studies; Human observational studies

https://www.peertechzpublications.com

Check for updates

\section{Jack E James*}

Reykjavík University, Menntavegur 1, 101 Reykjavík, Iceland

\section{Abstract \\ Rationale: The majority of pregnant women regularly consume caffeine, a habit-forming substance of no nutritional value for mother or baby.}

Objectives: To examine evidence of association between maternal caffeine consumption and childhood behavioural and neurocognitive development, and to consider the soundness of current health guidance concerning the consumption of caffeine during pregnancy.

Methods: Database searches identified a large pool of peer-reviewed articles, which when culled for relevance yielded a modest corpus of animal and human research for inclusion in this focussed narrative review of potential caffeine-related threats to childhood behavioural and neurocognitive development.

Results: High biological plausibility of potential harm from maternal caffeine exposure indicated by early animal research is confirmed by more recent animal studies that sought to mimic human consumption patterns. Reported negative outcomes include increased neuronal network excitability and susceptibility to seizures in offspring, and disruptions to electrophysiological activity, learning, and memory. In contrast, human observational studies have yielded inconsistent findings. Some studies have reported evidence of negative behavioural and neurocognitive outcomes, including hyperkinetic disorder, attention deficit disorder, and intelligence level in preschool- and elementary-aged children. Other studies, however, reported no associations with maternal caffeine consumption for similar parameters.

Conclusions: Current understanding of caffeine-related increased risk of harm for childhood development is limited due to inconsistent findings from human research. However, persistent reports of possible negative outcomes indicate high priority need for further research. In the meantime, the cumulative scientific evidence supports advice to pregnant women and women contemplating pregnancy to avoid caffeine.

Caffeine is the most widely consumed psychoactive substance in history [1]. Its consumption exceeds that of all other common drugs, including alcohol, nicotine, and the spectrum of licit and illicit substances humans ingest. For example, due to the "near universality of use of caffeine-containing beverages and foods" [2], the population consumption of alcohol, caffeine's likely closest rival as the world's most popular drug, falls far short of that for caffeine. The consumption of caffeine transcends almost every social barrier, including age, gender, geography, and culture. Whereas general estimates indicate that more than $80 \%$ of people worldwide regularly consume caffeine, the proportion of consumers is higher than that in many countries. In Canada, for example, 92 per cent of adults reported daily consumption of coffee or tea or both [3]. In the United States, 98 per cent of children aged five to 18 years were found to consume caffeine at least weekly, with consumption increasing steadily with age [4]. Indeed, caffeine is unusual among psychoactive compounds in being part of the daily diet of most people worldwide, including the majority of pregnant women $[5,6]$.

The high prevalence of maternal caffeine consumption persists despite decades of reports of potential harm in both animal and human studies [1,7-9]. In particular, evidence of negative clinical outcomes reported in original epidemiological studies and meta-analyses has increased over time in both consistency and volume. For example, among 14 meta-analyses published since the year 2000, maternal caffeine consumption was unanimously reported to be associated with increased risk for low birthweight and/or small for gestational age (5 meta-

Citation: James JE (2021) Maternal caffeine consumption and childhood behavioural and neurocognitive development: A focused narrative review. Arch Community Med Public Health 7(2): 111-119. DOI: https://dx.doi.org/10.17352/2455-5479.000148 
analyses), miscarriage (4 meta-analyses), childhood acute leukemia (3 meta-analyses), and stillbirth (2 meta-analyses) [8].

That maternal caffeine consumption remains commonplace is attributable, at least in part, to current health advice to women. The European Food Safety Authority [10], the United Kingdom National Health Service [11], and the American College of Obstetricians and Gynecologists [12] all advise that it is "safe" for pregnant women to consume up to $200 \mathrm{mg}$ caffeine (the approximate equivalent of 2 cups of moderatestrength coffee) per day. Such advice persists despite reports of significant dose-response associations suggestive of causation, including reports of no threshold of consumption below which associations between maternal caffeine consumption and adverse pregnancy outcomes are absent [8].

The diversity of adverse clinical outcomes is suggestive of potential disruption to key processes of foetal and child development. Nevertheless, developmental processes associated with potential harm have only recently begun to attract concerted research attention. Accordingly, the main aim of the present focussed review was to examine evidence of association between maternal caffeine consumption and childhood behavioural and neurocognitive development, including potential for long lasting sequelae. A review at this time may help to stimulate further research to clarify inconsistencies in reported findings, elucidate potential causal mechanisms, and identify directions for future research. Notwithstanding the need for further research, a second aim of the present review was to consider the implications of recent empirical findings for current health advice concerning maternal caffeine consumption.

\section{Caffeine pharmacology: Relevant mechanisms of action}

Caffeine is readily distributed throughout the body, and achieves peak plasma concentrations within approximately 40-60 minutes [13]. The drug crosses the placenta, exposing the developing fetus to concentrations similar to systemic levels in the mother $[14,15]$. Metabolism is principally by cytochrome P450 enzymes (monooxygenase and xanthine oxidase) in the liver, involving processes that are undeveloped in newborns and acquired during the first year of life $[16,17]$. Consequently, whereas adult caffeine elimination half-life is generally about 5 hours, 80 hours is typical of newborns [16].

Caffeine exerts a variety of pharmacological actions at diverse sites, both centrally and peripherally. These actions are due mostly to competitive blockade of the neuromodulator adenosine, with $\mathrm{A}_{1}$ and $\mathrm{A}_{2 \mathrm{~A}}$ receptors appearing to be the primary targets [18]. Effects include maintenance of transmitter release in the CNS (anti-somnolent effect), constriction of cerebral and coronary blood vessels, renal diuresis, respiratory bronchodilation, and gastrointestinal acid secretion [19-21]. $A_{1}$ and $A_{2 A}$ receptors also interact in functionally important ways with dopamine receptors $[22,23]$, with caffeine serving to stimulate secretion of the catecholamine stress hormones of epinephrine and norepinephrine [24]. In turn, elevated catecholamine levels have the potential to increase placental vasoconstriction and fetal heart rate [25], leading to impaired fetal oxygenation [26].

Acknowledgment of the high theoretical plausibility of fetal harm due to maternal caffeine consumption was the main impetus for early experimental studies with rodents (mice, rats, rabbits). A range of caffeine-induced gross fetal abnormalities was reported, including cleft palate, ectrodactyly (absent or deformed digits), and skeletal malformations [2730]. Responding to such reports, the United States Food and Drug Administration issued a warning advising pregnant women to restrict or eliminate coffee consumption [31]. The warning elicited wide discussion, including strenuous representation from caffeine-beverage industries [32]. Much comment focussed on the fact that animal studies frequently used caffeine doses exceeding the levels typical of human dietary intake [33], thereby drawing into question the adequacy of the animal models that had been used to test the human teratogenic potential of caffeine.

Doubts tended to be confirmed by early epidemiologic studies of humans, wherein significant associations between caffeine and/or coffee consumption and birth defects of the kind reported in animal studies were generally reported to be absent [34-38]. Over time, a consensus emerged around the inference that typical patterns of caffeine consumption are an unlikely cause of major physical birth defects in humans. That generally reassuring consensus appears to have encouraged wide acceptance of the reputed safety of "moderate" caffeine consumption during pregnancy. Notwithstanding beliefs about safe levels of intake, it is evident that current recommendations are often breached. For example, in one recent study, $41 \%$ of a cohort of pregnant women in Finland reported consuming more than the recommended maximum of $200 \mathrm{mg}$ caffeine per day [39], and in another study $25 \%$ of a cohort of pregnant Dutch women reported consuming more than $250 \mathrm{mg}$ caffeine per day [40].

Importantly, of numerous potential adverse pregnancy outcomes, gross morphological abnormality (i.e., "frank" teratogenicity) is but one category, attention to which may have unduly influenced current health guidelines $[1,7,9]$. As mentioned above, an extensive body of scientific evidence from human observational studies and meta-analyses has emerged independently of early studies of caffeine-related teratogenicity [8]. The more recent evidence of harm appears not to have been fully considered in relation to the framing of current health advice. Against that background, the current focussed review examines recent increased interest in extending the search for potential adverse outcomes of maternal caffeine consumption beyond clinical end states to include subtler, yet potentially no less important, threats in the form of disturbed childhood behavioural and neurocognitive development.

\section{Source literature}

PubMed and Google Scholar databases were searched by the author using key terms for caffeine exposure, exposure period (namely, pregnancy), and offspring outcomes. The exposure terms were "caffeine" and the main caffeine- 
containing beverages of "coffee", "tea", "cola", "energy drink", and "maté"). The search terms for the exposure period were "maternal" and "pregnancy". Other sources of caffeine, such as chocolate (including confectionaries, cake, and hot drink), cocoa, and decaffeinated coffee and tea were not included as specific search terms, as they generally represent a negligible fraction of total daily caffeine consumed. Moreover, studies of caffeine beverages frequently include results for the aforementioned "other" sources (sometimes reported for purposes of comparison with the main sources), thereby contributing to the likelihood of information from low-caffeine sources, where relevant, being included as part of the present review. Additionally, it was assumed that the term "caffeine" would capture relevant studies (if any) that had examined a substantial source of caffeine other than those identified by the specific search terms employed here. The search was further refined by inclusion of terms relevant to the key "development"|"developmental" outcomes of interest. These were "behavioural", "cognitive", and "neurocognitive" outcomes, and the developmental stages of "neonate", "neonatal", "postnatal", "newborn", "infant", "child", "childhood, and "children". In turn, articles were handsearched for additional records.

A total of 1,283 English-language articles published up to and including 31 January 2021 were identified. These were culled to select only those studies that reported empirical findings for the association between caffeine exposure during pregnancy and specific offspring outcomes for postnatal and/ or childhood behavioural and/or neurocognitive development. Additionally, whereas earlier literature is discussed to provide background that informs the current state of knowledge, empirical studies published since 2009 were selected as the focus for the current narrative review. The selection process involving the aforementioned criteria yielded a core literature base of 14 articles, comprised of five experimental rodent studies and nine human epidemiological studies (see Table 1).

\section{Experimental studies with rodents}

Early experiments with rodentsprovided strong confirmation of high biological plausibility for harm from maternal caffeine exposure, with consistent reports of disruption to behavioural and neurocognitive development [41-43]. For example, Grimm and Frieder [41] exposed pregnant rat dams to daily doses of $0.15,0.30$ or $0.45 \mathrm{mg} / \mathrm{ml}$ caffeine in drinking water for the last 7 days of gestation. Compared to untreated controls, offspring exposed to the low dose $(0.15 \mathrm{mg} / \mathrm{ml})$ evidenced hyperactivity in an open-field task, and offspring exposed to the high dose $(0.45 \mathrm{mg} / \mathrm{ml})$ evidenced disruption to complex visual and auditory discrimination learning. Foreshadowing later observational research with humans [44-47], Grimm and Frieder [41] reported that the medium $(0.30 \mathrm{mg} / \mathrm{ml})$ and high $(0.45 \mathrm{mg} / \mathrm{ml})$ doses also led to increased weight observable at 35 days, with weight gains becoming progressively greater as the animals aged.

The salience of the Grimm and Frieder [41] findings can be gauged by comparing the caffeine doses they used to typical human exposures. With the caveat that the translation of caffeine dosing in animal studies to human consumption patterns is complex and approximate, a dose of $0.30 \mathrm{mg} / \mathrm{ml}$ in drinking water was estimated by Silva, et al. [48] to produce plasma concentrations of caffeine in rat dams comparable to that found in the blood of humans drinking 3-4 cups of coffee per day. On the other hand, Li, et al. [49] estimated the same dose $(0.30 \mathrm{mg} / \mathrm{ml})$ of caffeine in drinking water to be comparable to the human consumption of about 2 cups of coffee per day. Thus, bearing in mind the approximate nature of such estimates, the Grimm and Frieder [41] "low" dose of $0.15 \mathrm{mg} / \mathrm{ml}$ and possibly the "medium" dose of $0.30 \mathrm{mg} /$ $\mathrm{ml}$, could be considered comparable to reputed "moderate" and "safe" levels of exposure during human pregnancy. In that vein, the $0.45 \mathrm{mg} / \mathrm{ml}$ dose would be comparable to intake widely considered "high", but not uncommon, among pregnant women.

Table 1 summarises key findings from five rodent studies published since 2009 that satisfied the aforementioned selection criteria for inclusion in the current narrative review. In contrast to the Grimm and Frieder [41] study, in which exposure was limited to the latter stages of pregnancy, Soellner, et al. [50] exposed pregnant rat dams to either plain tap water or caffeinated tap water throughout gestation. The level of caffeine exposure was estimated to be the human equivalent of 2 to 3 cups of coffee per day. Adult male and female offspring of dams exposed to caffeine during pregnancy exhibited memory and learning impairments in object recognition and spatial learning tasks. The findings were interpreted as suggesting developmental changes in the expression and/or function of adenosine receptors within the hippocampus and prefrontal cortex leading to long-term alterations in memory and learning. Long-term effects were also reported by Silva et al. [48] who exposed mouse dams to $0.30 \mathrm{mg} / \mathrm{ml}$ caffeine in drinking water throughout gestation and lactation. Compared to untreated controls, adult offspring of treated animals showed increased excitability in hippocampal circuits and associated sequelae including increased susceptibility to seizures.

Fazeli, et al. [51] also reported increased seizure susceptibility in a study in which caffeine in drinking water was intended to mimic human consumption of approximately three cups of coffee per day. Compared to control offspring, formation and activity of cortical networks was found to be impaired in offspring of caffeine-exposed mouse dams. In another study that sought to mimic human consumption patterns with the use of $0.30 \mathrm{mg} / \mathrm{ml}$ caffeine in drinking water, Zappettini, et al. [52] were careful to parallel human exposure before and during pregnancy until full-term birth, taking account of both the time span of caffeine exposure and amount of caffeine consumed. Electrophysiological recordings of hippocampal CA1 pyramidal cells in vitro revealed caffeinerelated changes likely to increase the risk for early onset of dementia-associated pathology. In addition, Li et al. [49] reported that expression of adenosine $A_{1}$ and $A_{2 A}$ receptors was impaired in fetal and neonatal brain among offspring of rat dams exposed to $20 \mathrm{mg} / \mathrm{kg}$ caffeine (compared to saline) administered twice daily via subcutaneous injection. The same study also reported that learning and memory were impaired in adult offspring exposed to caffeine in utero. 
Table 1: Summary of original animal and human studies concerning maternal caffeine consumption and childhood behavioural and neurocognitive development, published since year 2009.

\begin{tabular}{c|c|c|c|c|}
\hline Authors & Year & Main aim & Method & Keyndings
\end{tabular}

Experimental Studies with Rodents

Soellner, et al.

2009

Effects of chronic prenatal exposure Pregnant rat dams were exposed to caffeine on cognitive performance via drinking water to the human in adult male and female offspring. equivalent of 2 to 3 cups of coffee

2013 Effects of maternal exposure to caffeine, as an adenosine modulator on offspring neural development.

Silva, et al. consumption of 3 cups of coffee in during pregnancy and the early humans. postnatal period.

2018 Effects of maternal caffeine exposure on neurocognitive functions.

Zappettini,

The long-term consequences of early-life exposure to caffeine for Alzheimer's disease-like pathology.

et al. drinking water intended to mimic the

\section{Human observational studies}

Linnet, et al.

Associations between maternal coffee exposure and risk of hyperkinetic disorder and attention deficit hyperactivity disorder (ADHD). caffeine consumption and inattention/overactivity suggestive 18 -month-old children. of ADHD.

Loomans, et al.

2012 Associations between maternal caffeine consumption and offspring behavioural problems. per day throughout pregnancy, and offspring were compared to the offspring of caffeine-free dams.

Offspring of mouse dams exposed to Compared to untreated controls, caffeine-exposed $0.30 \mathrm{mg} / \mathrm{ml}$ caffeine via drinking water during pregnancy and lactatior compared to offspring of caffeine-free hippocampal circuitry during the first postnatal week, dams.

Caffeine was added to the drinking water of female mice to mimic daily

Rat dams received subcutaneous injections of $20 \mathrm{mg} / \mathrm{kg}$ caffeine (compared to saline) twice daily throughout pregnancy. Fetal and offspring body and brain weight were measured, learning- and memoryrelated receptors were measured, and learning and memory were tested in adult offspring.

The study employed a rodent model of Alzheimer's disease (THY-Tau22 transgenic mice). The exposure schedule involved caffeine in amount and time span of the human consumption of caffeine before and throughout gestation.

A prospective cohort study of 24,068 Danish children, including 88 children aged 3-12 years with hyperkinetic disorder and/or ADHD.

A prospective cohort study of 25,343 Norwegian mothers and their

A prospective cohort study in The

Compared to untreated controls, adult male and female offspring of caffeine-exposed dams exhibited impaired cognition, including 24-h memory retention in novel object recognition and spatial learning in a maze task. Findings were suggestive of developmental changes in the adenosine-receptor functioning in the hippocampus and prefrontal cortex, leading to long-term alterations in memory and learning. offspring showed delayed migration and insertion and increased neuronal network excitability and susceptibility to seizures. Adult offspring displayed loss of hippocampal GABA neurons and cognitive deficits.

Compared to controls, caffeine-exposed offspring showed impaired brain development, including altered construction of GABAergic neuronal networks in the primary visual cortex at postnatal days 6-7; increased synaptic activity in vitro and elevated network activity in vivo in the primary visual cortex; altered in vivo hippocampal network activity from the neonatal period until adulthood; and increased seizure susceptibility.

Compared to untreated controls, caffeine-exposed offspring showed fetal growth restriction, and longterm impairment in learning and memory; intrauterine programming dysfunction of adenosine receptors; and impairment of subunits of down-stream protein-binding systems in fetal, neonatal, and adult brain.

Caffeine-exposed offspring showed deficits in spatia learning and memory earlier than untreated controls; and disordered electrophysiological recordings suggestive of early onset of Alzheimer's disease-like pathology.

High maternal caffeine consumption $(10+$ cups of coffee per day) reported at 16 weeks of gestation was associated with a threefold increased risk of hyperkinetic disorder and ADHD. After adjustment for confounders, the risk decreased to RR $2.3(95 \% \mathrm{Cl} 0.9-5.9)$ and was no longer statistically significant.

After adjustment for potential confounders, caffeine in the form of soft drinks but not coffee or tea, reported at 17 and 30 weeks of gestation, was found to be associated with inattention/overactivity.

After adjustment for potential confounders, maternal caffeine consumption reported at 16 weeks of gestation was not associated with a higher risk for behaviour assessed at age $5-6$ years for mother- and teacher-reported problem problems or with suboptimal prosocial behaviour. behaviour. 
Galéra, et al. 2015

Associations between maternal caffeine consumption and impaired cognitive development in offspring.
A prospective cohort study of 1,083 French mother-child pairs followed from pregnancy to when the children were aged 5.5 years.

A prospective cohort study in the serum paraxanthine (the primary United States of 2,197 children metabolite of caffeine) and offspring assessed at ages 4 and 7 years. IQ and problem behaviour.

Del-Ponte, et al.

Associations between maternal consumption of caffeine during pregnancy and childhood ADHD.

A prospective cohort study of 3,485 Brazilian children assessed at age 11 years.

A prospective cohort study of 47,491

Associations between maternal caffeine consumption and offspring Danish mother-child pairs. behavioural and psychiatric disorders. neurodevelopment.
After adjustment for potential confounders, there was a significant caffeine-related association with reduced childhood IQ of nearly one full IQ point per additional $100 \mathrm{mg} /$ day of maternal caffeine intake assessed before pregnancy and after delivery.

After adjustment for potential confounders, no statistically significant associations were reported between maternal serum paraxanthine, measured at "early pregnancy" (<20 weeks) and "third trimester" (>26 weeks), and either IQ or problem behaviour.

After adjustment for potential confounders, maternal caffeine consumption, assessed by interview after delivery, was not associated with ADHD.

After adjustment for potential confounders, maternal caffeine consumption reported at 15 weeks gestation was reported to be associated with increased risk of a range of behavioural and psychiatric disorders.

After adjustment for potential confounders, maternal caffeine consumption reported at 22 weeks of gestation yielded no consistent associations with childhood neurodevelopment at any age.

After adjustment for potential confounders, MRI revealed caffeine-related alterations in brain microstructures associated with maternal caffeine consumption reported "throughout gestation".
In summary, recent animal studies confirm the decadeslong inference of high biological plausibility for potential harm from maternal caffeine exposure. The studies summarised in Table 1 report a wide range of caffeine-related disruption to brain function and structure, and associated developmental impairment in behaviour and cognition. Whereas there may have been a tendency to discount earlier similar findings due to pregnant animals being exposed to levels of caffeine in excess of those typical of human consumption patterns, the studies summarised in Table 1 were careful to use regimens of caffeine intake intended to mimic typical human exposure. As such, recent animal findings are important in raising awareness of potential negative effects for child development due to maternal caffeine consumption.

\section{Human observational studies}

Table 1 summarises key findings from nine recent prospective cohort studies of potential caffeine-related harm to childhood behavioural and neurocognitive development. It is evident from the table that diversity of investigatory approach and inconsistency in reported findings represent major challenges to interpreting the evidence. In an early study of caffeine and attention deficit hyperactivity disorder (ADHD), Linnet et al. [53] reported that high maternal caffeine consumption (defined as 10+ cups of coffee per day) was associated with a three-fold increased risk of ADHD-related behaviour among 24,068 Danish children aged between 3 and 12 years. However, adjustment for confounders reduced the estimated risk to RR 2.3 (95\% CI 0.9-5.9), which no longer represented a statistically significant difference.
Bekkhus, et al. [54] also reported a significant association for ADHD-related behaviour among 25,343 Norwegian children aged 18 months. In this instance, however, increased risk was observed for maternal consumption of soft drinks but not coffee and tea, leading the authors to suggest that caffeine was unlikely to be responsible for the reported effect. At the same time, the authors cautioned that the children may have been "too young" for caffeine-related effects to be reliably observed. In a study of 3,439 Dutch children, Loomans et al. [40] reported that maternal caffeine consumption was unrelated to mother and teacher ratings of ADHD-related behaviour among children aged 5 to 6 years. Absence of association was also reported by Klebanoff and Keim [55] in the United States for 2,197 children aged 4 and 7 years, and by Del-Ponte et al. [56] for 3,458 Brazilian children aged 11 years. Conversely, in a larger study of 47,491 Danish children aged 11 years, Mikkelsen et al. [57] reported that high maternal caffeine consumption (defined as $8+$ cups of coffee per day) assessed at 15 weeks of pregnancy was associated with increased risk for a range of behavioural and psychiatric disorders including ADHD-related behaviour.

In the same study that reported no association for ADHD-related behaviour, Klebanoff and Keim [55] found no association between maternal caffeine consumption and intelligence quotient (IO) in children aged 4 and 7 years. Conversely, Galéra et al. [6] reported a significant association between maternal caffeine consumption and lower IQ among 1,083 French children aged 5.5 years. Reasons for the discrepant findings were debated in an exchange of letters without the respective groups $[58,59]$ reaching agreement. Bernard, et al. [58] reasoned that a combination of the two sets of results 
supported the conclusion that a causal link exists between high caffeine exposure and lower childhood IQ. In reply, Klebanoff and Keim [59] reiterated their belief "that the amount of caffeine consumed by most pregnant women ... is not likely to be associated with reduced child cognition" (p. 873).

Unfortunately, inconsistencies in findings continue to characterise the most recent research. Berglundh, et al. [60] examined the association between maternal caffeine consumption and impaired neurodevelopment, including motor development, behaviour problems, and language difficulties, among 64,189 Norwegian children aged 6 and 18 months, and 3, 5 and 8 years, and found no consistent associations. Conversely, Christensen, et al. [61] in the United States, examined maternal caffeine consumption and regional brain microstructure among 9,157 children aged 9 to 10 years. Maternal exposure to caffeine was measured dichotomously to create an exposed group of women who reported consuming caffeine more than once a week throughout pregnancy and a group comprised of women who reported consuming caffeine less than once a week. Magnetic resonance imaging (MRI) indicated microstructure alterations of "critical fibre tracts" among children of the exposed group of mothers compared with children of control mothers,

\section{Limitations and inconsistencies among human observa- tional studies}

No one set of factors can explain all the inconsistencies in the reported findings from human observational studies of maternal caffeine consumption and childhood development. Notably, studies to date have been few in number and have involved participants in different countries with varying patterns of caffeine consumption. In addition, apart from being prospective in nature, studies have employed widely differing investigatory approaches. In particular, there has been little consistency in the measurement of maternal caffeine exposure, the population samples examined have differed greatly in size, children have been assessed at different ages, and different behavioural and neurocognitive developmental outcomes have been examined.

In addition to those inconsistencies, studies share a limitation common to much human observational research, namely, the challenge of controlling for potentially confounding variables. In this respect, it would be fair to say that studies have generally been carefully conducted. Among a wide range of potential confounders, including marital status, ethnicity, employment status, and education level of one or both parents, maternal smoking and alcohol consumption have received particular attention. Of the nine human observational studies summarised in Table 1, all adjusted for cigarette smoking, and all but one [61] adjusted for alcohol consumption.

Recall bias in relation to amount of caffeine consumed during pregnancy has long been offered as a possible source of confounding, especially by commentators with caffeineindustry affiliations [62-66]. However, as with many recent studies concerning clinical outcomes associated with maternal caffeine consumption [8], all of the observational studies summarised in Table 1 employed prospective designs. Consequently, recall bias is an unlikely source of confounding in those studies, since caffeine consumption was assessed in advance of assessment of indicators of childhood behavioural and neurocognitive development. For example, Linnet, et al. [53] assessed maternal caffeine consumption at 16 weeks of pregnancy, and developmental outcomes were assessed when the children were aged between 3 and 12 years. Similarly, Mikkelsen, et al. [57] assessed maternal caffeine consumption at 15 and 30 weeks of pregnancy, and developmental outcomes were measured when the children were aged 11 years. Likewise, Berglundh, et al. [60] assessed caffeine consumption at 22 weeks of pregnancy, and developmental outcomes were measured when the children were aged 6 and 18 months, and 3, 5 and 8 years.

Notwithstanding likely absence of recall bias, lack of consistency in the specific methods used to measure caffeine consumption during pregnancy could account for inconsistencies in the findings. In most studies, caffeine intake during pregnancy was assessed by means of self-report questionnaire, administered in person or by mail. Typically, participants were asked to report the number of servings (e.g. cups, mugs, glasses, or bottles) of caffeine beverages (e.g., coffee, tea, or caffeinated soft drinks). In some, but not all studies, participants reported information concerning method of preparation (e.g., instant, espresso, percolated, or filtered coffee), and responses were aggregated to derive estimates of milligrams of caffeine consumed per day. Typically, studies provided little or no information concerning the reliability and validity of the measurements used. Only one study, that of Klebanoff and Keim [55], used an objective biomarker of caffeine exposure in the form of serum paraxanthine, the primary metabolite of caffeine.

\section{Public-health advice}

Even in the absence of other information, the status of caffeine as a common habit-forming substance of no nutritional value to either mother or baby is a clear indicator of the need to adopt a cautionary approach when framing public-health advice about consuming the drug during pregnancy. In respect of potential harm to childhood behavioural and neurocognitive development, findings from animal studies add substantial additional grounds for concern. On the other hand, the relative paucity of human observational studies, and especially the many contradictory results among the few that have been conducted, preclude definitive conclusions. However, whereas contradictory findings may incline some commentators to be dismissive, precisely the opposite inclination is warranted. The core empirical fact concerning potential caffeine-related developmental harm is that some studies have reported null results whereas others have not. Therefore, unless and until maternal caffeine consumption is consistently shown to be without risk to childhood development, persistent intermittent empirical findings of harm should figure prominently in health advice for mothers and mothers-to-be.

Recent guideline revisions hint at possible growing circumspection among relevant health authorities. Specifically,

Citation: James JE (2021) Maternal caffeine consumption and childhood behavioural and neurocognitive development: A focused narrative review. Arch Community Med 
in keeping with the hitherto broad consensus, the Dietary Guidelines for Americans Committee, 2015 (DGAC) [67] advised women of the reputed safety of consuming $200 \mathrm{mg}$ caffeine per day during pregnancy. However, that advice is absent from the recently-revised Dietary Guidelines for Americans, 2020-2025 [68]. Instead of continuing to condone the consumption of reputedly "safe" amounts of caffeine during pregnancy, the new Guidelines state that women "who could be or who are pregnant should consult their healthcare providers for advice concerning caffeine consumption" (p. 118).

We may guess that this revised advice is an attempt at compromise, reflecting growing awareness of the many and increasing reports of harm associated with maternal caffeine consumption. However, the revised DGAC [68] guidance is disappointing at least, and even shocking in its prevarication. Following a protracted process of review of scientific literature, open public consultation, and extensive stakeholder (including industry) consultation, all under the guidance of a select group of experts, the DGAC [68] aims to deliver dietary advice that is clear and direct. However, in this instance, on a subject of relevance to the majority of women, the DGAC has effectively said that is has no opinion. In so doing, the DGAC has opted to transfer responsibility for advice about maternal caffeine consumption to an amorphous and countless number of individual "healthcare providers", the large majority of whom may be assumed to possess neither the required expertise nor any clear means for mustering an informed opinion.

\section{Future research}

Whereas current knowledge is limited concerning caffeinerelated risks to childhood behavioural and neurocognitive development, there are many facts about maternal caffeine consumption that are far from uncertain. As discussed above, there is high biological plausibility for potential harm; there is consistent evidence from animal research of harm to behavioural and neurocognitive development among offspring (summarised in Table 1); and extensive evidence from human observational research and meta-analyses of harm for diverse clinical pregnancy outcomes [8]. The inconsistent findings described herein (and summarised in Table 1) from human observational studies of childhood behavioural and neurocognitive development serve, at the very least, to indicate the high-priority need for more and better-controlled studies in this area.

For the present, it is not possible to be highly prescriptive as to what constitutes better-controlled studies in this relatively undeveloped field. Animal experimentation offers the substantial advantage of permitting controlled manipulations of caffeine exposure and should be pursued so as inform researchers about potentially important human sites of caffeine-related harm (e.g., impaired development of critical brain structures). Alas, comparable levels of experimental control, such as may be achieved in randomised controlled trials, although theoretically possible, are unlikely to be conducted in practice due to the questionable ethicality of conducting such trials with pregnant women $[8,69]$.
Consequently, advances in the field are likely to depend on continued epidemiological investigation. Here, much benefit would accrue were greater standardisation achieved in relation to the use of reliable and validated measurement protocols for assessing caffeine exposure, such as has been in use for some time in the Norwegian Mother and Child Cohort Study [70,71]. Similarly, continued attention to the control of potential confounders is strongly advised, including where possible the use of biological indicators of exposure, not only for caffeine but also for nicotine and alcohol.

\section{Conclusion}

There are strong grounds for eschewing the complacency that may be said to characterise much current public-health advice about maternal caffeine consumption. Taken as a whole, the cumulative scientific evidence supports advice to pregnant women and women contemplating pregnancy to avoid caffeine.

\section{References}

1. James JE (1991) Caffeine and health. London: Academic Press.

2. Gilbert RM (1984) Caffeine consumption. In G. A. Spiller (Ed.), The methylxanthine beverages and foods: Chemistry, consumption, and health effects. New York: Alan R. Liss 185-214.

3. Gilbert RM (1976) Caffeine as a drug of abuse. In R. J. Gibbins, Y. Israel, H. Kalant, R. E. Popham, W. Schmidt, \& R. G. Smart (Eds.), Research advances in alcohol and drug problems. New York: Wiley \& Sons 3: 49-176.

4. Morgan KJ, Stults VJ, Zabik ME (1982) Amount and dietary sources of caffeine and saccharin intake by individuals ages 5 to 18 years. Regul Toxicol Pharmacol 2: 296-307. Link: https://bit.ly/3cFORCA

5. Frary CD, Johnson RK, Wang MQ (2005) Food sources and intakes of caffeine in the diets of persons in the United States. J Am Diet Assoc 105: 110-113. Link: https://bit.ly/3zrxHAv

6. Galéra C, Bernard JY, van der Waerden J, Bouvard MP, Lioret S, et al. (2016) Prenatal caffeine exposure and child IQ at age 5.5 years: The EDEN motherchild cohort. Biol Psychiatry 80: 720-726. Link: https://bit.ly/3zIQM7f

7. James JE (1997) Understanding caffeine: A biobehavioral analysis. Thousand Oaks, CA: Sage Publications. Link: https://bit.ly/3clUjTd

8. James JE (2020) Maternal caffeine consumption and pregnancy outcomes: A narrative review with implications for advice to mothers and mothers-to-be. BMJ Evid Based Med 25: 10. Link: https://bit.ly/3iLYL7B

9. James JE, Paull I (1985) Caffeine and human reproduction. Rev Environ Health 7: 151-167. Link: https://bit.ly/3vqEyXy

10. European Food Safety Authority (2015) Panel on Dietetic Products, Nutrition and Allergies. Scientific opinion on the safety of caffeine. EFSA Journal 13 4102.

11. NHS (2018) Should I limit caffeine during pregnancy? United Kingdom National Health Service. Link: https://bit.ly/3wuz1AS

12. American College of Obstetricians and Gynecologists Committee (2016) Moderate caffeine consumption during pregnancy. Link: https://bit.ly/2SxBk7e

13. Rall TW (1990) Drugs used in the treatment of asthma. The methylxanthines, cromolyn sodium, and other agents. In Gilman, A. G., Rall, T. W., Nies, A. S. \& Taylor, P. (eds.) Goodman and Gilman's the pharmacological basis of therapeutics. New York: Pergamon. 
14. Horning MG, Butler CM, Nowlin J, Hill RB (1975) Drug metabolism in the human neonate. Life Sci 16: 651-671. Link: https://bit.ly/35i6na6

15. Darakjian LI, Kaddoumi A (2019) Physiologically based pharmacokinetic/ pharmacodynamic model for caffeine disposition in pregnancy. Mol Pharm 16: 1340-1349. Link: https://bit.ly/3iOLgnw

16. Parsons WD, Neims AH (1981) Prolonged half-life of caffeine in healthy term newborn infants. J Pediatr 98: 640-641. Link: https://bit.ly/3xebfsK

17. Pearlman SA, Duran C, Wood MA, Maisels MJ, Berlin CM (1989) Caffeine pharmacokinetics in preterm infants older than 2 weeks. Dev Pharmacol Ther 12: 65-69. Link: https://bit.ly/3wql32B

18. Dunwiddie TV, Masino SA (2001) The role and regulation of adenosine in the central nervous system. Annu Rev Neurosci 24: 31-55. Link: https://bit.ly/3gzxjr1

19. Franchetti P, Messini L, Cappellacci L, Grifantini M, Lucacchini A, et al. (1994) 8-Azaxanthine derivatives as antagonists of adenosine receptors. J Med Chem 37: 2970-2975. Link: https://bit.ly/3il9fFg

20. LeBlanc J, Soucy J (1994) Hormonal dose-response to an adenosine recepto agonist. Can J Physiol Pharmacol 72: 113-116. Link: https://bit.ly/35pesd7

21. Carter AJ, O'Connor WT, Carter MJ, Ungerstedt U (1995) Caffeine enhances acetylcholine release in the hippocampus in vivo by a selective interaction with adenosine A1 receptors. J Pharmacol Exp Ther 273: 637-642. Link: https://bit.ly/2SACVJt

22. Garrett BE, Holtzman SG (1994) D1 and D2 dopamine receptor antagonists block caffeine-induced stimulation of locomotor activity in rats. Pharmacol Biochem Behav 47: 89-94. Link: https://bit.ly/3ilhXmA

23. Ferré S (2016) Mechanisms of the psychostimulant effects of caffeine: implications for substance use disorders. Psychopharmacology 233: 19631979. Link: https://bit.ly/2TxE1pL

24. Lane JD, Pieper CF, Phillips-Bute BG, Bryant JE, Kuhn CM (2002) Caffeine affects cardiovascular and neuroendocrine activation at work and home. Psychosom Med 64: 595-603. Link: https://bit.ly/3cla640

25. Kirkinen P, Jouppila P, Koivula A, Vuori J, Puukka M (1983) The effect of caffeine on placental and fetal blood flow in human pregnancy. Am J Obstet Gynecol 147: 939-942. Link: https://bit.ly/3pVHaf5

26. Resch BA, Papp JG (1983) Effects of caffeine on the fetal heart. American Journal of Obstetrics and Gynecology 146: 231-232.

27. Fujii T, Nishimura $H$ (1972) Adverse effects of prolonged administration of caffeine on rat fetus. Toxicol Appl Pharmacol 22: 449-457. Link: https://bit.ly/3vqlKb8

28. Nishimura H, Nakai K (1960) Congenital malformations in offspring of mice treated with caffeine. Proc Soc Exp Biol Med 104: 140-142. Link: https://bit.ly/3iDP9vL

29. Palm PE, Arnold EP, Rachwall PC, Leyczek JC, Teague KW, et al. (1978) Evaluation of the teratogenic potential of fresh-brewed coffee and caffeine in the rat. Toxicol Appl Pharmacol 44: 1-16. Link: https://bit.ly/3xo4x3u

30. Terada M, Nishimura $H$ (1975) Mitigation of caffeine induced teratogenicity in mice by prior chronic caffeine ingestion. Teratology 12: 79-82. Link: https://bit.ly/3xrGrF3

31. Goyan J (1980) Food and Drug Administration news release, No. P80-36. Washington DC:FDA.

32. James JE (2002) "Third-party" threats to research integrity in public-private partnerships. Addiction 97: 1251-1255. Link: https://bit.ly/35kjVB

33. Thayer P, Palm P (1975) A current assessment of mutagenic and teratogenic effects of caffeine. CRC Crit Rev Toxicol 5: 345-380. Link: $h$ ttps://bit.ly/3vs6Yk5
34. Furuhashi N, Sato S, Suzuki M, Hiruta M, Tanaka M, et al. (1985) Effects of caffeine ingestion during pregnancy. Gynecol Obstet Invest 19: 187-191. Link: https://bit.ly/3cJZZfN

35. Kurppa K, Holmberg PC, Kuosma E, Saxen L (1983) Coffee consumption during pregnancy and selected congenital malformations: A nation wide casecontrol study. Am J Public Health 73: 1397-1399. Link: https://bit.ly/2RZbNUq

36. Linn S, Schoenbaum SC, Monson RR, Rosner B, Stubblefield PG, et al. (1982) No association between coffee consumption and adverse outcomes of pregnancy. N Engl J Med 306: 141-145. Link: https://bit.ly/35mUWOg

37. McDonald AD, Armstrong BG, Sloan M (1992) Cigarette, alcohol, and coffee consumption and congenital defects. Am J Public Health 82: 91-93. Link: https://bit.ly/3cHIOLI

38. Rosenberg L, Mitchell AA, Shapiro S, Slone D (1982) Selected birth defects in relation to caffeine-containing beverages. JAMA 247: 1429-1432. Link: https://bit.ly/3pSz9CR

39. Lehtonen A, Uusitalo L, Auriola S, Backman K, Heinonen S, et al. (2020) Caffeine content in newborn hair correlates with maternal dietary intake. Eur J Nutr 59.

40. Loomans EM, Hofland L, Van der Stelt O, van der Wal MF, Koot HM, et al. (2012) Caffeine intake during pregnancy and risk of problem behavior in 5-to 6-year-old children. Pediatrics 130: e305- e313. Link: https://bit.ly/3xoV3Fg

41. Grimm VE, Frieder B (1988) Prenatal caffeine causes long lasting behavioral and neurochemical changes. Int $\mathrm{J}$ Neurosci 41: 15-28. Link: https://bit.ly/3pSVbdr

42. Hughes RN, Beveridge IJ (1990) Sex-and age-dependent effects of prenatal exposure to caffeine on open-field behavior, emergence latency and adrenal weights in rats. Life Sci 47: 2075-2088. Link: https://bit.ly/3pYoE5F

43. Nakamoto T, Roy G, Gottschalk SB, Yazdani M, Rossowska M (1991) Lasting effects of early chronic caffeine feeding on rats' behavior and brain in later life. Physiol Behav 49: 721-727. Link: https://bit.ly/3pSXNrL

44. Chen LW, Murrin CM, Mehegan J, Kelleher CC, Phillips CM, et al. (2019) maternal, but not paternal or grandparental, caffeine intake is associated with childhood obesity and adiposity: The Lifeways Cross-Generation Cohort Study. Am J Clin Nutr 109: 1648-1655. Link: https://bit.ly/3cCWIEz

45. Li J, Luo H, Wu Y, He Z, Zhang L, et al. (2015) Gender-specific increase in susceptibility to metabolic syndrome of offspring rats after prenatal caffeine exposure with post-weaning high-fat diet. Toxicol Appl Pharmacol 284: 3453 3453. Link: https://bit.ly/3goc2Sg

46. Papadopoulou E, Botton J, Brantsæter AL, Haugen M, Alexander J, et al. (2018) Maternal caffeine intake during pregnancy and childhood growth and overweight: Results from a large Norwegian prospective observational cohort study. BMJ Open 8: e018895. Link: https://bit.ly/2U6RIlb

47. Voerman E, Jaddoe VW, Gishti O, Hofman A, Franco OH, et al. (2016) Materna caffeine intake during pregnancy, early growth, and body fat distribution at school age. Obesity 24: 1170-1177. Link: https://bit.ly/3grdMtO

48. Silva CG, Métin C, Fazeli W, Machado NJ, Darmopil S, et al. (2013) Adenosine receptor antagonists including caffeine alter fetal brain development in mice. Sci Transl Med 5: 197-204. Link: https://bit.ly/3gu8oVM

49. Li Y, Zhang W, Shi R, Sun M, Zhang L, et al. (2018) Prenatal caffeine damaged learning and memory in rat offspring mediated by ARs/PKA/CREB/BDNF pathway. Physiol Res 67: 975-983. Link: https://bit.ly/35qbrZO

50. Soellner DE, Grandys T, Nuñez JL (2009) Chronic prenatal caffeine exposure impairs novel object recognition and radial arm maze behaviors in adult rats. Behav Brain Res 205: 191-199. Link: https://bit.ly/3gtfqtW

51. Fazeli W, Zappettini S, Marguet SL, Grendel J, Esclapez M, et al. ( 2017) Earlylife exposure to caffeine affects the construction and activity of cortical networks in mice. Exp Neurol 295: 88-103. Link: https://bit.ly/35sO0z3

Citation: James JE (2021) Maternal caffeine consumption and childhood behavioural and neurocognitive development: A focused narrative review. Arch Community Med Public Health 7(2): 111-119. DOI: https://dx.doi.org/10.17352/2455-5479.000148 
52. Zappettini S, Faivre E, Ghestem A, Carrier S, Buée L, et al. (2019) Caffeine consumption during pregnancy accelerates the development of cognitive deficits in offspring in a model of tauopathy. Front Cell Neurosci 13: 438. Link: https://bit.ly/3xrGNLT

53. Linnet KM, Wisborg K, Secher NJ, Thomsen PH, Obel C, et al. (2009) Coffee consumption during pregnancy and the risk of hyperkinetic disorder and ADHD: A prospective cohort study. Acta Paediatrica 98: 173-179. Link: https://bit.ly/3vk4eFm

54. Bekkhus M, Skjøthaug T, Nordhagen R, Borge Al (2010) Intrauterine exposure to caffeine and inattention/overactivity in children. Acta Paediatr 99: 925-928. Link: https://bit.ly/3zrwKrV

55. Klebanoff MA, Keim SA (2015) Maternal serum paraxanthine during pregnancy and offspring body mass index at ages 4 and 7 years. Epidemiology 26: 185191. Link: https://bit.ly/2TqcMgF

56. Del-Ponte B, Santos IS, Tovo-Rodrigues L, Anselmi L, Munhoz TN, et al. ( 2016) Caffeine consumption during pregnancy and ADHD at the age of 11 years: A birth cohort study. BMJ Open 6: e012749. Link: https://bit.ly/35mSp6I

57. Mikkelsen SH, Obel C, Olsen J, Niclasen J, Bech BH (2017) Maternal caffeine consumption during pregnancy and behavioral disorders in 11-year-old offspring: A Danish National Birth Cohort study. J Pediatr 189: 120-127. Link: https://bit.ly/2TyanAl

58. Bernard JY, Heude B, Galéra C (2016) Maternal caffeine intake during pregnancy and child cognition and behavior at 4 and 7 years of age. American Journal of Epidemiology 183: 871-872. Link: https://bit.ly/3zuwmZw

59. Klebanoff MA, Keim SA (2016) Maternal caffeine intake during pregnancy and child cognition and behavior at 4 and 7 years of age. American Journal of Epidemiology 183: 872-873. Link: https://bit.ly/3gpCc7b

60. Berglundh S, Vollrath M, Brantsæter AL, Brandlistuen R, Solé-Navais P, et al. (2021) Maternal caffeine intake during pregnancy and child neurodevelopment up to eight years of age: Results from the Norwegian Mother, Father and Child Cohort Study. Eur J Nutr 60: 791-805. Link: https://bit.ly/3gxhlls

61. Christensen ZP, Freedman EG, Foxe JJ (2021) Caffeine exposure in utero is associated with structural brain alterations and deleterious neurocognitive outcomes in 9-10 year old children. Neuropharmacology 186: 108479. Link: https://bit.ly/3guK2wx
62. Leviton A (1988) Caffeine consumption and the risk of reproductive hazards J Reprod Med 33: 175-178.

63. Leviton A (2018) Biases inherent in studies of coffee consumption in early pregnancy and the risks of subsequent events. Nutrients 10: 1152. Link: https://bit.ly/2Szba4a

64. Peck JD, Leviton A, Cowan LD (2010) A review of the epidemiologic evidence concerning the reproductive health effects of caffeine consumption: A 20002009 update. Food Chem Toxicol 48: 2549-2576. Link: https://bit.ly/3zu63CQ

65. Wikoff D, Welsh BT, Henderson R, Brorby GP, Britt J, et al. (2017) Systematic review of the potential adverse effects of caffeine consumption in healthy adults, pregnant women, adolescents, and children. Food Chem Toxicol 109: 585-648. Link: https://bit.ly/3cD0k3Z

66. Doepker C, Franke K, Myers ., et al. (2018) Key findings and implications of a recent systematic review of the potential adverse effects of caffeine consumption in healthy adults, pregnant women, adolescents, and children. Nutrients 10: 1536. Link: doi:10.3390/nu10101536"

67. Dietary Guidelines Advisory Committee (2015) Scientific report of the 2015 Dietary Guidelines Advisory Committee. Washington DC: US Department of Agriculture, Agricultural Research Service. Link: https://bit.ly/3zpHRBz

68. Dietary Guidelines Advisory Committee Dietary Guidelines for Americans, 2020-2025 (2020) US Department of Agriculture and US Department of Health and Human Services, $9^{\text {th }}$ Edition December 2020. Link: https://bit.ly/3vril6e

69. Jahanfar S, Jaafar SH (2015) Effects of restricted caffeine intake by mothe on fetal, neonatal and pregnancy outcomes. Cochrane Database Syst Rev 6.

70. Modzelewska D, Bellocco R, Elfvin A, Brantsæter AL, Meltzer HM, et al (2019) Caffeine exposure during pregnancy, small for gestational age birth and neonatal outcome: results from the Norwegian Mother and Child Cohort Study. BMC Pregnancy Childbirth 19: 80. Link: https://bit.ly/3pUOWaC

71. Sengpiel V, Elind E, Bacelis J, Nilsson S, Grove J, et al. (2013) Maternal caffeine intake during pregnancy is associated with birth weight but not with gestational length: Results from a large prospective observational cohort study. BMC Med 11: 42. Link: https://bit.ly/3cHzHLe
Discover a bigger Impact and Visibility of your article publication with

\section{Peertechz Publications}

Highlights

* Signatory publisher of ORCID

* Signatory Publisher of DORA (San Francisco Declaration on Research Assessment)

* Articles archived in worlds' renowned service providers such as Portico, CNKI, AGRIS, TDNet, Base (Bielefeld University Library), CrossRef, Scilit, J-Gate etc.

* Journals indexed in ICMJE, SHERPA/ROMEO, Google Scholar etc.

* OAI-PMH (Open Archives Initiative Protocol for Metadata Harvesting)

* Dedicated Editorial Board for every journal

- Accurate and rapid peer-review process

* Increased citations of published articles through promotions

* Reduced timeline for article publication

Submit your articles and experience a new surge in publication services (https://www.peertechz.com/submission).

Peertechz journals wishes everlasting success in your every endeavours.

Copyright: (C) 2021 James JE. This is an open-access article distributed under the terms of the Creative Commons Attribution License, which permits unrestricted use, distribution, and reproduction in any medium, provided the original author and source are credited. 